\section{Bringing Digital Urban Models into the Classroom - Potentials and \\ Constraints for Web GIS and \\ Collaborative Leaming}

GI_Forum 2018, Issue 2

Page: 207 - 213

Short Paper

Corresponding Author:

burgholzermi@sbg.ac.at

DOI: 10.1553/giscience2018_02_s207

\author{
Michael Burgholzer and Angela Hof \\ University of Sa lzb urg, Austria
}

\begin{abstract}
In the context of a competency-oriented teaching and leaming culture, a cooperative leaming environment is created in which leamers construct a common digital, multilayered city model in Google My Maps. The aim is that students should gain an advanced understanding of urban models and urban structure and acquire methodological skills in the use of Web GIS. This urban model focusses on the spatial distribution of urban soil sealing (imperviousness), urban green spaces, and the spatial distribution of population, facilities and workplaces, rather than land use and the layout of a city.
\end{abstract}

\title{
Keywords:
}

urban model, Web GIS, cooperative lea ming, Google My Maps, urban ecology

\section{Introduction}

The present paper draws on the didactic, theoretical and conceptual reasoning outlined below. These multiple arguments are transferred into a learning environment in schools that is a fully-fledged concept for working with digital urban models in Web GIS.

\section{Theoretical background}

The educational standards for Geography in schools published by the German Society for Geography (DGfG, 2014) embrace the 'system' concept as fundamental to the discipline. Geography focuses on the Earth system; it explains patterns and relationships in physical and human geographical subsystems, and the spatial expression of the components of these systems at different scales. Thereby, 'Spaces are [...] always considered as systems' (DGfG, 2014, p. 10). Consequently, structure, function and process are subconcepts of the system perspective (DGfG, 2014, p. 10). Wiktorin (2014) discusses the revival of models in Geography teaching in schools to support the development of several competencies. She underscores the didactical use of working with models and emphasizes urban models as particularly instructive for Geography teaching. However, she also cautions that critical reflectivity should be an integral component of teaching using models, given their potential 
for normative and over-simplified explanatory power. In order to avoid this pitfall and at the same time to make the most of the potentials of teaching using theoretical models that have an explicit spatial component, Wiktorin suggests three approaches. First, to teach modelbased thinking by inductive teaching methods in order to sensitize learners to the process of model-making, and to allow for adaptation of the model in accordance with one's own observations and understandings of the phenomena being studied. Second, to compare different and even controversial models for the same topic or phenomenon in order to foster an understanding of positionality. Finally, she argues that an extended understanding of models can be achieved only if learners develop a conceptual understanding of them in tandem with working with models as a procedural learning experience.

\section{Didactical reasoning for using digital urban models as a learning environment in schools}

Beyond the theoretical considerations, the motivation to develop a learning environment in schools based on digital urban models in Web GIS derives from the following assumptions and convictions. First, we contend that it is possible to develop digital urban models with students using technology that is not itself perceived as a GIS system, and which is accessible on a range of mobile devices. Therefore, the application was developed using Google My Maps as the final platform for the learning environment. Second, this technical approach fosters cooperative learning, as different approaches to the model building and visualization of results can be shared instantaneously among members of the group of learners. The models are at the same time both a means and a product of the students' communication about the urban model; the students reveal through their working mode the procedural elements of creating the models. Third, students experience the constraints and trade-offs that have to be accommodated in the model-making process in order to adhere to the necessities of simplification while ensuring the clarity of the key message that the model conveys.

\section{Creating a digital urban model as a learning environment}

An urban model is understood here as an abstract, typified, digital, dynamic representation and visualization of the urban system, with its human geographical subsystems and its physical geographical and material subsystems. In order to comply with Wiktorin's (2014) request that models for teaching Geography in schools should have relevance in the current scientific discourse, the model we created combines urban ecology concepts with urban and social geography ones. A structural urban model often focuses on the land use and layout of a city, its functional dimension and historical development, including more recent developments like de-industrialization, suburbanization and gentrification (De Lange \& Weiss, 2014). In contrast, the focus of our model is on the spatial distribution of urban soil sealing (i.e. imperviousness), urban green spaces, and the spatial distribution of population, facilities and workplaces. 


\section{Data layers used in the model}

In Austria, census tracts (Zäblsprengel in German) represent the highest level of detail of demographic and census data. In the Salzburg City case study area, there are 192 census tracts, and demographic data for the 2015 census was analysed (Magistrat der Stadt Salzburg, 2017).

The European Urban Atlas provides pan-European, inter-comparable, high-resolution landuse and land-cover data for urban areas with more than 100,000 inhabitants for the reference year 2012 at a spatial resolution of $10 \mathrm{~m}$ (European Environment Agency, 2017). The categories of the Urban Atlas cover green, grey and blue infrastructure and give details on the level of imperviousness or soil sealing as the most important ecological determinant of the urban system (Pauleit, 2016).

To make the influence of soil sealing transparent, traceable and comprehensible, the data layer for imperviousness is part of the urban model. It captures the spatial distribution of artificially sealed areas, as well as the level of sealing of the soil per area unit. Maintained over long periods of time, these artificial surfaces determine the material urban structure. Students can observe that the built-up area classifications in the Urban Atlas are based on the level of soil sealing, represented in the imperviousness layer at $20 \mathrm{~m}$ spatial resolution (Umweltbundesamt, 2018). This choice of model parameters exploits the potential to use models for inductive approaches that make urban structures and processes accessible and understandable for learners. Simplification in the form of typification (e.g. land use categories) and complexity reduction (leaving aside certain aspects) support deep learning and understanding of complex human and physical geographical systems in a spatial perspective (see Wiktorin 2014).

\section{Data preparation in open source and proprietary GIS software for use in Google My Maps}

Google My Maps is freely available, no desktop program is required, the user interface is very simple, and it offers learners the opportunity to work collaboratively and simultaneously on a single project. The disadvantages of the Web GIS are the limited data processing functionality and import features (Table 1). 
Table 1: Properties of va rious GIS a pplic a tions

\begin{tabular}{|c|c|c|c|c|}
\hline & $\begin{array}{l}\text { Google } \\
\text { My } \\
\text { Maps }\end{array}$ & QGIS & $\begin{array}{l}\text { ArcGIS } \\
\text { Online }\end{array}$ & $\begin{array}{l}\text { ArcGIS } \\
\text { Desktop }\end{array}$ \\
\hline Web browser client & $\sqrt{ }$ & & $\sqrt{ }$ & \\
\hline Works regardless of the operating system ${ }^{1}$ & $\sqrt{ }$ & $\sqrt{ }$ & $\sqrt{ }$ & \\
\hline Free for everyone / open source & $\sqrt{ }$ & $\sqrt{ }$ & & \\
\hline Collaborative editing (shift workers) & $\sqrt{ }$ & & $\sqrt{ }$ & \\
\hline Simultaneous collaborative editing & $\sqrt{ }$ & & & \\
\hline Import and edit raster data directly & & $\sqrt{ }$ & & $\sqrt{ }$ \\
\hline Import and edit shapefiles directly & & $\sqrt{ }$ & $\sqrt{ }$ & $\sqrt{ }$ \\
\hline $\begin{array}{l}\text { Import map features from large files } \\
(>5 \mathrm{MB})\end{array}$ & & $\sqrt{ }$ & $\sqrt{ }$ & $\sqrt{ }$ \\
\hline Raster-to-vector conversion (vectorization) & & $\sqrt{ }$ & & $\sqrt{ }$ \\
\hline
\end{tabular}

QGIS allows the preparation of the data layers used in our model (Table 1). Simplifying and generalizing the data is necessary to comply with the technical functionality of the future learning environment. In addition, the following steps have the advantage for learners of reducing the initial didactic input:

- The Urban Atlas data is clipped to the city area of Salzburg. All polygon features classified as 'green urban area' are selected and saved as new dataset.

- The soil sealing raster data is aggregated and vectorized, and all features with an average degree of sealing over $40 \%$ are extracted. Soil sealing above $40 \%$ has an enormous impact on urban ecosystem services such as temperature regulation, precipitation infiltration or surface runoff (see Pauleit, 2016).

After these preparatory steps, the students can be provided with the following data:

- Vector data of census tracts

- Statistical data of main residences, workplaces, facilities and age class distribution

- Vector data of urban soil sealing (above 40\%)

- Vector data of urban green spaces according to the Urban Atlas definition

- Data that is integrated within Google My Maps (Google Maps as a searchable base map).

\section{Exploring data layers for inductive urban modelling by the students}

Different relationships and interdependencies between structure and function in the city can be explored by analysing the types of urban green space (e.g. parks) and its distribution in relation to the density of built-up areas in terms of level of soil sealing, population density,

\footnotetext{
${ }^{1}$ Windows, MacOS and Linux
} 
age class distribution and workplaces. After introducing the learning environment (e.g. with a video tutorial) and explaining work assignments, students import the demographic data into the Google My Maps attribute table and use the area measurement feature of the Web GIS to display and analyse the sealing per capita. Learners should also consider how to make appropriate visualizations for modelling, and whether any visualization capabilities are missing in Google My Maps. Different model representations may be used (e.g. Figure 1).

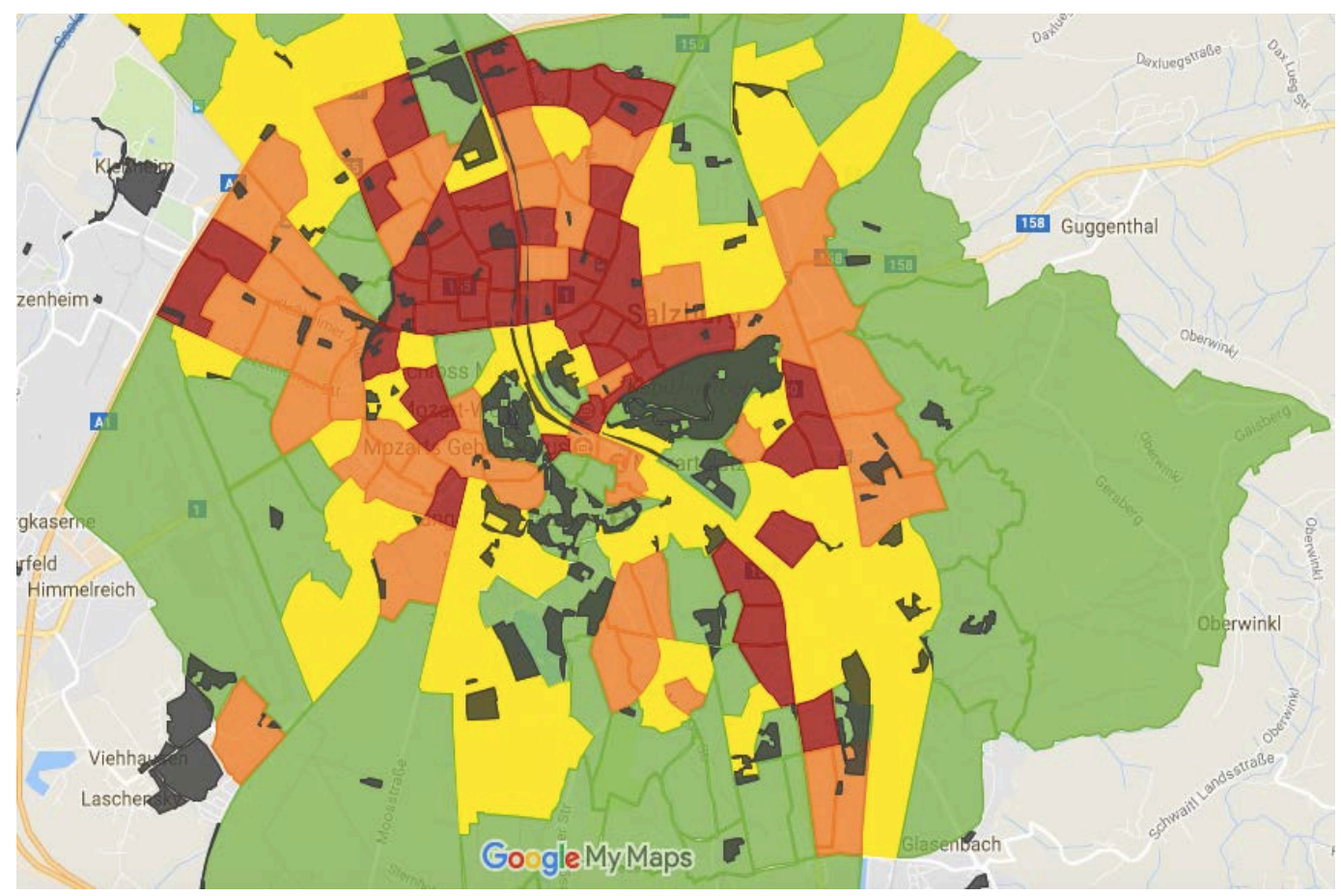

Figure 1: In this example of a possible visualization by leamers, the population density of the census tracts of Salzburg, classified into four equal intervals of low (=green), middle (= yellow and orange) and high population density (=red), is overlaid with the transparent Urban Atlas vector data of the urban green areas (resulting in dark green map colour). Data source: Urban Atlas \& Municipal Authority of the City of Salzburg; Background map: Google Maps

The learners can also get data through Google My Maps' built-in base map, for example by using the search feature to locate facilities such as shopping centres, banks, post offices or other infrastructure locations. These can be located by their own point features and described and compared with the data for the population density.

One of the most obvious difficulties to be resolved by the students when developing the urban model is the delineation of the urban area itself. Students encounter difficulties when analysing patterns and ratios of data, such as urban green space per inhabitant, or urban land use (built-up area or density) per inhabitant. Overlaying the census tract boundaries with the Urban Atlas shows that administrative units (i.e. the census tracts) that are the basis for social and demographic data are not congruent with what intuitively is identified as the urban, 
hence built-up area (Figure 1). Learners perceive that indicator numbers and ratios are sensitive to the boundaries used for calculating them.

To avoid conflicts in real-time editing, students or groups of students can be assigned to particular census tracts. This also results in better verifiability of the students' work by the teacher. The result is a mosaic of the city structure according to thematic layers, which the learners combine into a city-wide model.

The learning environment created here involves collaborative learning, i.e. learning in which students work together to develop knowledge, supported by computer science systems (see Haake et al., 2009, p. 2). There is a common goal that can only be achieved through the work of all group participants. By updating Google My Maps, students will always have access to the shared attribute table and the visualizations of other group participants. They can compare different solutions and reflect on their own product. The learners can also ask other students who have already found a suitable solution for help.

\section{Discussion and outlook}

If the teacher already has advanced experience of working with the GIS application, the preparation steps outlined above can be completed in about 30-60 minutes. If not, dealing with GIS may be a significant initial hurdle, requiring a longer training period or the selection of alternative data for the model.

In this learning environment, the digital model represents a communication medium for the students. It allows for inductive learning in which students support each other by sharing model building and visualization results (cf. Wiktorin, 2014). Thus, important advantages of cooperative learning are exploited, as other perspectives on the topic are opened up (Janneck, 2009, p. 26) and self-directed work, without constant intervention by the teacher, is possible (Grune \& De Witt, 2009, pp. 28-30). Comparing both the results of students' models on the same topic and their models to other city models also corresponds to Wiktorin's (2014) approaches.

This approach could also be used to explore various processes. For example, overlaying maps of urban climate on the Urban Atlas data would allow students to focus on the impact of inner-city urban green spaces on air temperature (park cool island effect). Another option would be to have students monitor, over a week or two, data that is published by the city administration on particulate matter, ozone levels and air temperature for a number of measurement stations in the city. The students could map these point data and - based on the spatial data and their knowledge of the everyday traffic and weather conditions of the period - hypothesize about the relationships and interdependencies between soil sealing, weather, traffic, thermal load and air quality. 


\section{Burgholzer \& Hof}

\section{References}

De Lange, E. \& Weiss, S. (2014). Das Strukturmodell der deutschen Stadt. Praxis Geographie Extra. Modelle in der Geographie. Thematische und didaktische Einordnung, 23-24.

DGfG (German Society for Geography). (2014). Educational Standards in Geography for the Intermediate School Certificate with sample assignments, eighth edition. Retrieved from http://geographiedidaktik.org/wpcontent/uploads/2014/11/edu_standards_geo_3_2014_web.pdf

European Environment Agency. (2017). Urban Atlas. Retrieved from https://www.eea.europa.eu/data-and-maps/data/urban-atlas

Grune, C., \& De Witt, C. (2009). Pädagogische und didaktische Grundlagen. In J. Haake, G. Schwabe, \& M. Wessner (Eds.), CSCL-Kompendium. Lehr- und Handbuch zum computerunterstützten kooperativen Lernen. München, Wien: Oldenbourg, 27-41.

Haake, J., Schwabe, G. \& Wessner M. (2009). Einleitung und Begriffe. In Haake, J., Schwabe, G. \& Wessner M. (Eds.), CSCL-Kompendium. Lehr- und Handbuch zum computerunterstützten kooperativen Lernen. München, Wien: Oldenbourg, 1-13.

Janneck, M. (2009). Lern- und kommunikationspsychologische Grundlagen. In J. Haake, G. Schwabe, \& M. Wessner (Eds.), CSCL-Kompendium. Lehr-und Handbuch zum computerunterstützten kooperativen Lernen. München, Wien: Oldenbourg, 14-26.

Magistrat der Stadt Salzburg. (2017). Salzburg in Zahlen. Statistische Zählbezirke und Zählsprengel. Retrieved from https://www.stadt-

salzburg.at/internet/bildung_kultur/salzburg_in_zahlen/statistische_zaehlbezirke_und_zaehlspre n_251948.htm

Pauleit, S. (2016). Welche Beziehungen bestehen zwischen der räumlichen Stadtstruktur und den ökologischen Eigenschaften der Stadt? In Breuste, J., Pauleit, S., Haase, D. \& Sauerwein, M. (Eds.), Stadtökosysteme. Funktion, Management und Entwicklung. Berlin, Heidelberg: Springer, 23-60.

Umweltbundesamt (2017). High Resolution Layer Versiegelung 2012. Retrieved from http://www.umweltbundesamt.at/umweltsituation/umweltinfo/opendata/oed_landbedeckung

Wiktorin, D. (2014). Modelle in der Geographie: Vernetzt denken, kritisch reflektieren, kompetent anwenden. Praxis Geographie Extra. Modelle in der Geographie. Thematische und didaktische Einordnung, 611. 